06;09;03

\title{
Формирование кремниевых наночастиц методом импульсной лазерной абляции пористого кремния в жидкостях
}

\author{
(C) А.В. Скобёлкина ${ }^{1}$, Ф.В. Кашаев ${ }^{1}$, А.В. Колчин ${ }^{1}$, Д.В. Шулейко ${ }^{1}$, Т.П. Каминская ${ }^{1}$, \\ Д.Е. Преснов ${ }^{1-3}$, Л.А. Головань ${ }^{1}$, П.К. Кашкаров ${ }^{1,4}$ \\ ${ }^{1}$ Московский государственный университет им. М.В. Ломоносова, Москва, Россия \\ ${ }^{2}$ Научно-исследовательский институт ядерной физики им. Д.В. Скобельцына Московского государственного \\ университета им. М.В. Ломоносова, Москва, Россия \\ ${ }^{3}$ Центр квантовых технологий Московского государственного университета им. М.В. Ломоносова, Москва, Россия \\ 4 Национальный исследовательский центр „Курчатовский институт“, Москва, Россия \\ E-mail: snastya.19996@mail.ru
}

Поступило в Редакцию 26 марта 2020г.

В окончательной редакции 26 марта 2020г.

Принято к публикации 10 апреля 2020 г.

Показано, что абляция слоев мезо- и микропористого кремния пикосекундными лазерными импульсами в воде и этаноле приводит к формированию суспензий нанокремния диаметром менее $100 \mathrm{~nm}$. Продемонстрировано, что использование пористого кремния позволяет уменьшить пороги лазерной абляции и увеличить концентрацию частиц в суспензиях по сравнению со случаем абляции кристаллического кремния.

Ключевые слова: импульсная лазерная абляция, пористый кремний, атомно-силовая микроскопия, порог абляции.

DOI: 10.21883/PJTF.2020.14.49659.18312

В последнее время активно исследуется применение кремниевых наночастиц (КНЧ) для решения разнообразных биомедицинских задач [1-3]. Этот интерес к КНЧ обусловлен их высокой биосовместимостью, биоразлагаемостью и низкой токсичностью. Для эффективного введения в биологические ткани частицы должны иметь размер менее $100 \mathrm{~nm}$. Методы механического измельчения или ультразвукового измельчения, традиционно применяемые для пористого или кристаллического кремния (КК), не позволяют обеспечить требуемый размер [4]. Между тем формирование наночастиц диаметром менее $100 \mathrm{~nm}$ возможно в результате импульсной лазерной абляции в жидкости; получаемые при этом суспензии КНЧ являются химически чистыми [3]. Однако выход продукта реакции в данном случае весьма небольшой, что осложняет использование КНЧ ввиду их низкой концентрации в суспензии. Чтобы преодолеть данный недостаток, можно формировать КНЧ с помощью лазерной абляции пористого кремния (ПК) - нанокомпозитной среды, образованной нанокристаллами кремния, разделенными нанопорами [5]. ПК можно изготовить методом электрохимического травления КК в электролите. В зависимости от свойств исходной пластины КК и электролита происходит формирование слоя микропористого кремния (микро-ПК), в котором размер пор и нанокристаллов не превышает $10 \mathrm{~nm}$, или мезопористого кремния (мезо-ПК), в котором размер пор и нанокристаллов находится в пределах 10-50 nm. Полученные в результате указанного двухстадийного процесса (первый этап - формирование слоя ПК методом электрохимического травления, второй этап - лазерная абляция
ПК) КНЧ широко востребованы в биомедицинских приложениях в качестве фотолюминесцентных меток [6], контрастирующих агентов в оптической когерентной томографии [7], фотосенсибилизаторов синглетного кислорода в фотодинамической терапии [7]. Однако для формирования образцов, пригодных для перечисленных выше приложений, необходимо знать параметры лазерного излучения, позволяющие получать КНЧ с заданной структурой. Одним из основных параметров является величина порога абляции, т.е. минимальной плотности энергии, достаточной для эффективного выноса вещества мишени и образования кратера на поверхности материала. Помимо этого следует определить размеры КНЧ и их концентрации в суспензии после окончания процесса абляции.

Для формирования слоев микро-ПК и мезо-ПК были использованы пластины монокристаллического кремния $p$-типа с ориентацией поверхности (100) и удельными сопротивлениями $10-20 \Omega \cdot \mathrm{cm}$ и $17-23 \mathrm{~m} \Omega \cdot \mathrm{cm}$ соответственно, которые были подвергнуты электрохимическому травлению в течение $30 \mathrm{~min}$ в водном растворе плавиковой кислоты и этанола с плотностью тока $75 \mathrm{~mA} / \mathrm{cm}^{2}$ [8]. Толщины сформированных слоев микро-ПК и мезо-ПК оценивались с помощью сканирующего электронного микроскопа (СЭМ) Carl Zeiss Supra 40 и составили 25 и $80 \mu \mathrm{m}$ соответственно.

Для определения порогов абляции проводилось одноимпульсное облучение пластины КК и слоев микро-ПК и мезо-ПК импульсами лазера EKSPLA 2143A (1064 nm, $30 \mathrm{ps}$ ) с энергиями от 0.3 до $5 \mathrm{~mJ}$. Лазерное излучение фокусировалось линзой с фокусным расстоянием $40 \mathrm{~mm}$ 
Таблица 1. Рассчитанные значения пороговых энергий абляции $\left(\mathrm{J} / \mathrm{cm}^{2}\right)$ для КК и ПК, аблированных в воде, этаноле и на воздухе

\begin{tabular}{c|c|c|c}
\hline Буферная среда & КК & Мезо-ПК & Микро-ПК \\
\hline Вода & $1.26 \pm 0.11$ & $0.68 \pm 0.05$ & $0.18 \pm 0.02$ \\
Этанол & $1.18 \pm 0.09$ & $0.63 \pm 0.04$ & $0.41 \pm 0.04$ \\
Воздух & $0.86 \pm 0.09$ & $1.21 \pm 0.06$ & $0.41 \pm 0.02$
\end{tabular}

Таблица 2. Концентрация $(\mathrm{mg} / \mathrm{ml})$ наночастиц КК и ПК, аблированных в воде и этаноле

\begin{tabular}{c|c|c|c}
\hline Буферная среда & КК & Мезо-ПК & Микро-ПК \\
\hline Вода & 0.5 & 0.56 & 0.42 \\
Этанол & 0.52 & 0.56 & 0.5
\end{tabular}

на поверхность материала на воздухе или под слоем дистиллированной воды или этанола толщиной $5 \mathrm{~mm}$. После каждого лазерного импульса подложка смещалась с помощью шагового двигателя. Для определения порогов абляции для всех облученных материалов с помощью оптического микроскопа OLYMPUS BX41 были измерены радиусы сформированных кратеров $R$ (рис. $1, a, b)$ и получена зависимость величины $R^{2}$ от энергии лазерного импульса $E$ (типичная зависимость приведена на рис. 1, $a$ ).

Для лазерного пучка с гауссовым распределением поля для случая одного импульса энергии $E$ квадрат радиуса абляционного кратера линейно зависит от плотности энергии $F$, связанной с энергией в импульсе $E$ :

$$
R^{2}=\omega_{0}^{2} \ln \left(F / F_{t h}\right),
$$

где

$$
F=2 E / \pi \omega_{0}^{2}
$$

$\omega_{0}$ - радиус гауссова пучка по уровню интенсивности $1 / e^{2}, F_{t h}-$ пороговая плотность энергии. Как видно из рис. $1, a$, зависимость $R^{2}(E)$ близка к линейной. Таким образом, радиус $\omega_{0}^{2}$ можно определить по графику $R^{2}(E)$, используя линейную аппроксимацию функции. Далее значения лазерной энергии можно перевести в плотность энергии. Порог абляции $F_{a b l}$ определяется путем экстраполяции указанной зависимости до нулевого значения ординаты $\left(R^{2}\right)$ [9,10]. Зависимости диаметра кратера от плотности энергии абляции в жидких средах обладают схожим характером и демонстрируют его увеличение при росте энергии во всем диапазоне используемых значений.

Исходя из анализа морфологии поверхности для процесса одноимпульсной абляции можно сделать выводы о механизмах поглощения лазерной энергии материалом мишени. Линейное уменьшение радиуса кратера при уменьшении энергии воздействия лазерного излучения позволяет предположить вклад процесса двухфотонного
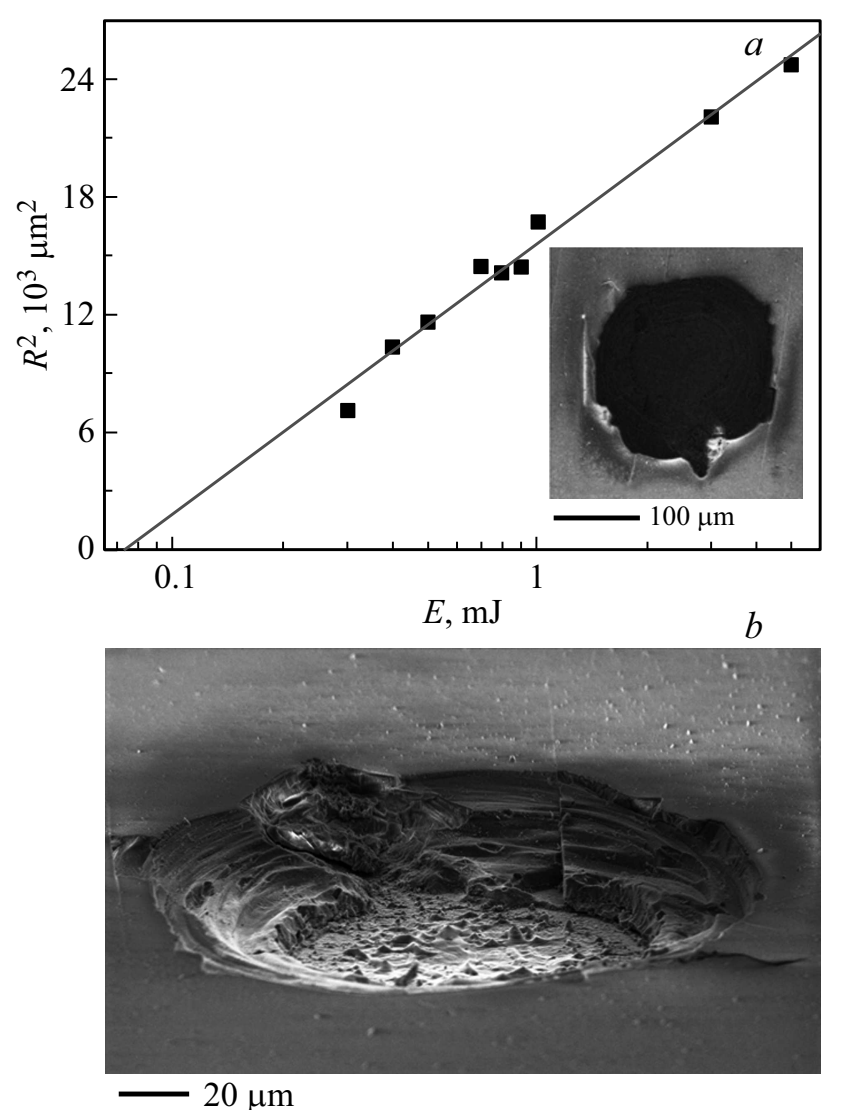

Рис. 1. $a-$ экспериментальная зависимость $R^{2}$ от $E$ (точки) для одноимпульсного лазерного воздействия на микро-ПК в воздухе и ее линейная аппроксимация (прямая). Полученные значения $\omega_{0}^{2}=5986 \pm 316 \mu \mathrm{m}^{2}, F_{t h}=0.41 \pm 0.02 \mathrm{~J} / \mathrm{cm}^{2}$. На вставке - СЭМ-изображение кратера после одноимпульсного лазерного воздействия на микро-ПК в воздухе. $b-\mathrm{CЭМ-изоб-}$ ражение кратера под углом $45^{\circ}$ после одноимпульсного лазерного воздействия на микро-ПК в воздухе.

поглощения во время одноимпульсной обработки кремния. При уменьшении энергии растет вклад многофотонных процессов, которые приводят к уменьшению площади абляционного пятна [11]. Следует отметить, что линейный характер кривой позволяет сделать вывод о том, что при достаточно большой энергии абляции будет наблюдаться вылет больших кусков материала. Рассчитанные значения пороговых энергий абляции в воде и этаноле представлены в табл. 1. Необходимо отметить снижение порога абляции для частиц ПК по сравнению с таковым для исходного КК.

Для определения возможности использования полученных образцов в биомедицинских приложениях была измерена концентрация КНЧ в сформированных суспензиях (табл. 2). Для образцов КНЧ мезо-ПК наблюдается увеличение концентрации частиц в единице объема, однако полученные значения не превышают предельную допустимую концентрацию для биологических экспериментов [2]. Таким образом, использование двухстадий- 

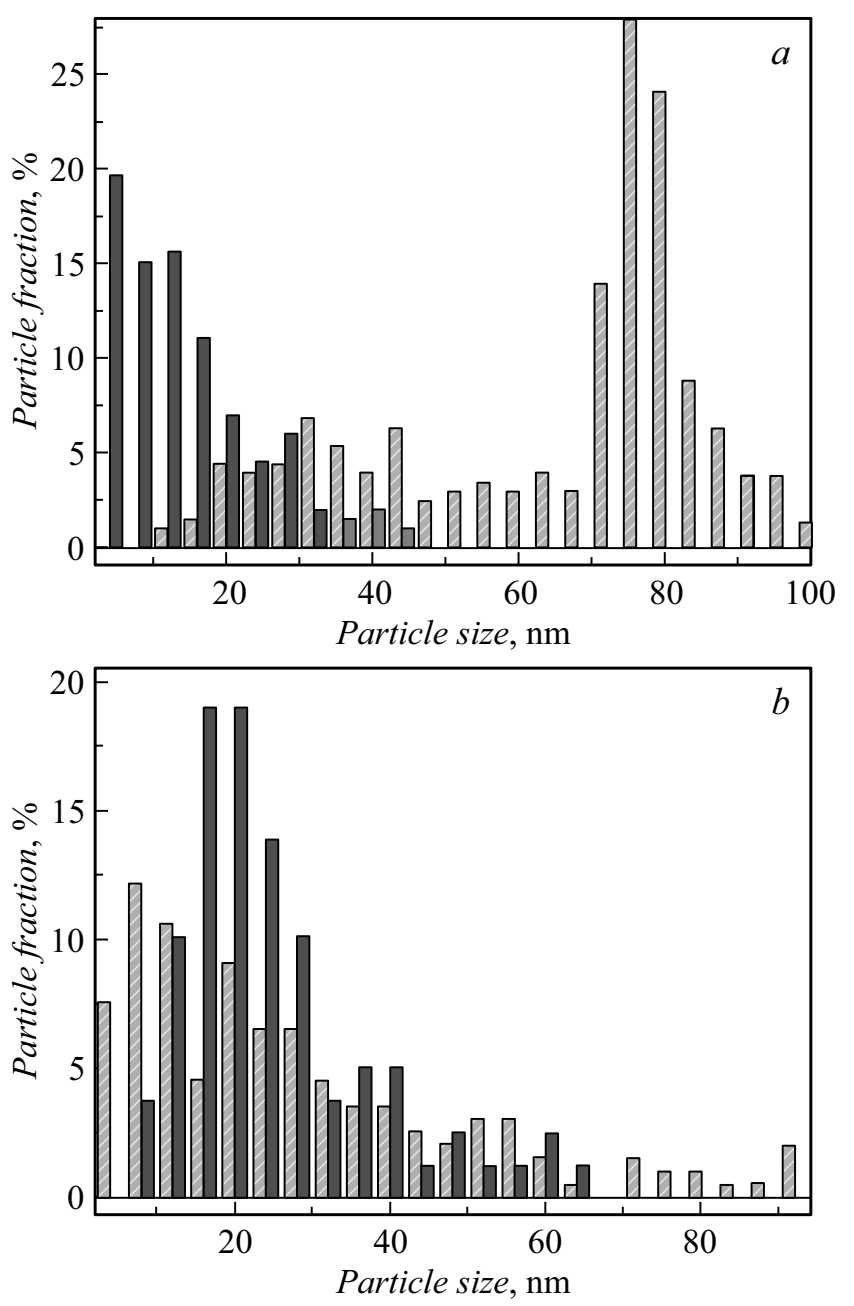

Рис. 2. Гистограммы распределения аблированных частиц микро-ПК (светлые столбцы) и мезо-ПК (темные столбцы) по размерам. $a-$ в дистиллированной воде, $b-$ в этаноле.

ной методики позволяет повысить качество получаемых суспензий.

Для нахождения распределения по размерам аблированных частиц из ПК проводился анализ изображений, полученных с помощью атомно-силового микроскопа ND-MDT Solver-PRO. Полученные гистограммы сравнивались с данными СЭМ. Анализ изображений наночастиц ПК, полученных с помощью последовательного использования методов электрохимического травления и пикосекундной лазерной абляции в дистиллированной воде и этаноле, выявил наличие фракции наночастиц размером менее $20 \mathrm{~nm}$ (рис. 2), что расширяет перспективы и возможности их применения по сравнению с механически измельченным ПК с точки зрения внедрения в биологические ткани. Следует отметить, что при абляции в этаноле доля таких частиц больше, чем при абляции в воде (рис. 2). Данная особенность может свидетельствовать как о меньшей эффективности агломерации в наночастицы продуктов абляции в буферных средах этанола, чем в воде, так и о возникновении фракции частиц с относительно крупными размерами (от 65 до $100 \mathrm{~nm}$ ) в воде за счет возможной коагуляции КНЧ в агломераты. Наличие фракции крупных агломератов КНЧ подтверждается также данными СЭМ. Также, согласно результатам, полученным методом СЭМ для всех типов КНЧ, они имеют гладкую без заметных поверхностных шероховатостей, близкую к сферической форму [12], что, по нашему мнению, должно способствовать введению частиц в биологические ткани с минимальными механическими повреждениями последних.

Для анализа кристалличности сформированных КНЧ были измерены спектры комбинационного рассеяния света (КРС) с использованием рамановского микроскопа Horiba Jobin Yvon HR 800 при возбуждении $\mathrm{Ar}^{+}$-лазером с длиной волны $488 \mathrm{~nm}$. Спектры КРС (рис. 3) для микро-ПК и мезо-ПК в воде и этаноле свидетельствуют о наличии кристаллической фазы кремния, соответствующей волновому числу $520 \mathrm{~cm}^{-1}$, и аморфной фазы, соответствующей диапазону $480-510 \mathrm{~cm}^{-1}$. Спектры образцов, полученных при абляции в воде и этаноле, схожи. В случае абляции мезо-ПК в воде наблюдается
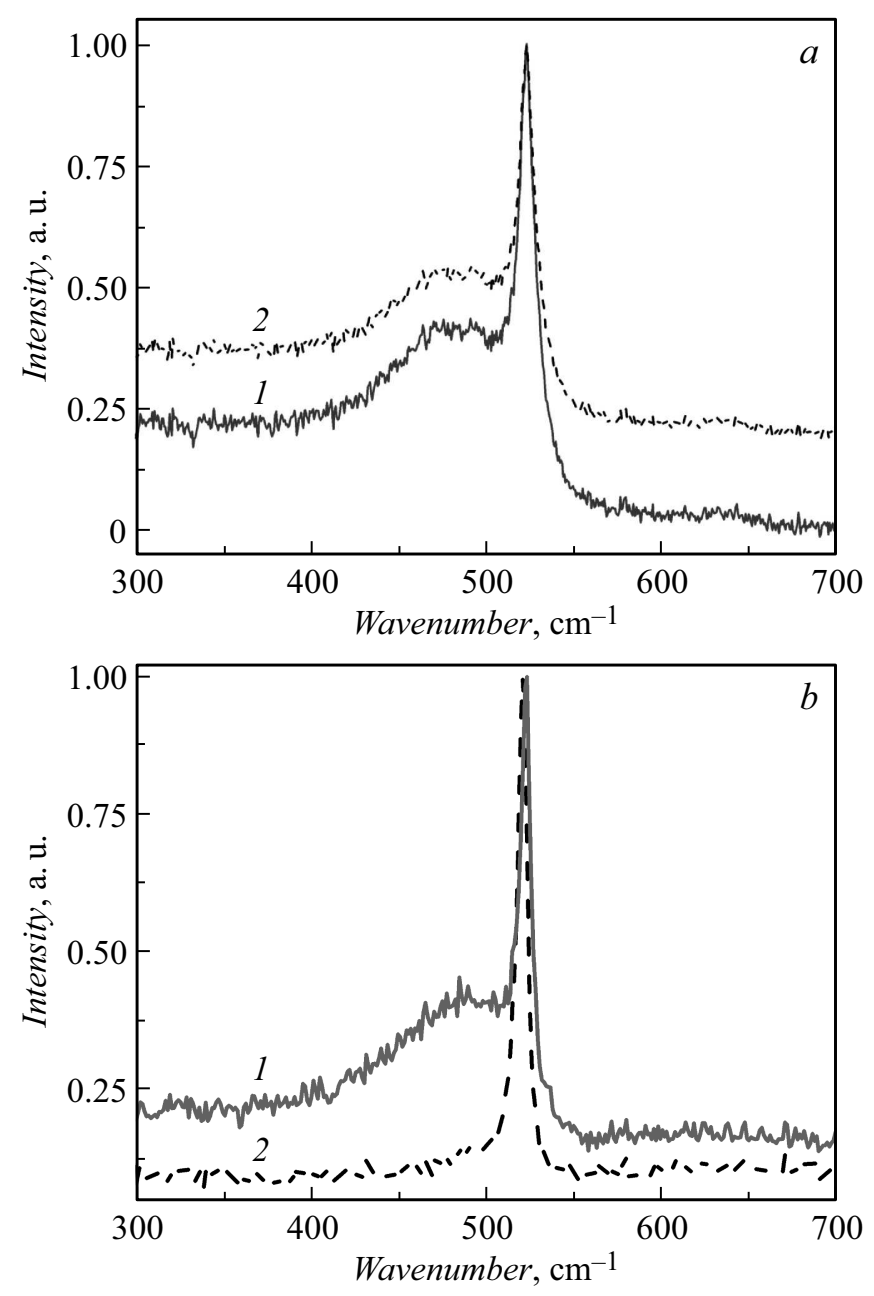

Рис. 3. Спектры КРС кремниевых наночастиц для микро-ПК $(a)$ и мезо-ПК $(b)$, аблированных в воде $(1)$ и этаноле (2). 
увеличение доли аморфной фазы по сравнению с абляцией в этаноле (рис. 3).

Таким образом, результаты работы показывают возможность формирования КНЧ с размерами менее $100 \mathrm{~nm}$ сферической формы путем пикосекундной лазерной абляции пластин ПК в воде и этаноле. Полученные частицы обладают высокой степенью кристалличности, сниженным порогом абляции по сравнению с КК, что позволяет рассматривать использование данных КНЧ в приложениях фотоники и биомедицины.

\section{Благодарности}

При проведении исследований использовалось оборудование Учебно-методического центра литографии и микроскопии МГУ им. М.В. Ломоносова.

\section{Финансирование работы}

Работа подготовлена при финансовой поддержке Российского фонда фундаментальных исследований (грант № 18-32-00884 мол_а).

\section{Конфликт интересов}

Авторы заявляют, что у них нет конфликта интересов.

\section{Список литературы}

[1] Bimbo L.M., Sarparanta M., Santos H.A., Airaksinen A.J., Mäkilä E., Laaksonen T., Peltonen L., Lehto V.-P., Hirvonen J., Salonen J. // ACS Nano. 2010. V. 4. N 6. P. 3023-3032.

[2] Ксенофонтова О.И., Васин А.В., Егоров В.В., Бобыль А.В., Солдатенков Ф.Ю., Теруков Е.И., Улин В.П., Улин Н.В., Киселев О.И. // ЖТФ. 2014. Т. 84. В. 1. С. 67-78.

[3] Gongalsky M.B., Osminkina L.A., Pereira A., Manankov A.A., Fedorenko A.A., Vasiliev A.N., Solovyev V.V., Kudryavtsev A.A., Sentis M., Kabashin A.V. // Sci. Rep. 2016. V. 6. P. 24732.

[4] Заботнов С.В., Кашаев Ф.В., Шулейко Д.В., Гонгальский М.Б., Головань Л.А., Кашкаров П.К., Логинова Д.А., Агрба П.Д., Сергеева Е.А., Кириллин М.Ю. // Квантовая электроника. 2017. Т. 47. № 7. С. 638-646.

[5] Handbook of porous silicon / Ed. L. Canham. Cham: Springer, 2018. $1613 \mathrm{p}$.

[6] Tolstik E., Osminkina L.A., Matthäus C., Burkhardt M., Tsurikov K.E., Natashina U.A., Timoshenko V.Y., Heintzmann R., Popp J., Sivakov V. // Nanomed.: Nanotechnol. Biol. Med. 2016. V. 12. N 7. P. 1931-1940.

[7] Тимошенко В.Ю., Кудрявщев А.А., Осминкина Л.А., Воронцов А.С., Рябчиков Ю.В., Белогорохов И.А., Ковалев Д., Кашкаров П.К. // Письма в ЖЭТФ. 2006. Т. 83. B. 9. C. $492-495$.

[8] Скобёлкина А.В., Кашаев Ф.В., Колчин А.В., Каминская Т.П., Заботнов С.В., Головань Л.А., Логинова Д.А., Хилов А.В., Агрба П.Д., Кириллин М.Ю. // Уч. зап. физ. фак-та МГУ. 2018. № 4. С. $1841302(1-9)$.
[9] Локтионов Е.Ю., Протасов Ю.С., Протасов Ю.Ю. // Инж. журн.: наука и инновации. 2013 № 10. DOI: $10.18698 / 2308-6033-2013-10-1036$

[10] Stuart B.C., Feit M.D., Herman S., Rubenchik A.M., Shore B.W., Perry M.D. // Phys. Rev. B. 1996. V. 53. N 4. P. 1749-1761.

[11] Kautek W., Krausz J., Lenzner M., Sartania S., Spielmann C., Kraisz F. // Appl. Phys. Lett. 1996. V. 69. N 21. P. 3146-3148.

[12] Skobelkina A.V., Kashaev F.V., Zabotnov S.V., Kolchin A.V., Kaminskaya T.P., Presnov D.E., Sergeeva E.A., Kirillin M.Yu., Golovan L.A., Kashkarov P.K. // 4th Int. Conf. on nanotechnologies and bomedical engineering (ICNBME 2019) / Eds. I. Tiginyanu, V. Sontea, S. Railean. Cham: Springer, 2019. V. 77. P. 101-104. 